\title{
ISOLAMENTO SOCIAL: Percepções Discentes Sobre o Deslocamento das Interações Acadêmicas Para Meios Digitais
}

\author{
Rafael Winícius da Silva Bueno ${ }^{1}$ \\ Thelma Duarte Brandolt Borges ${ }^{2}$ \\ Valderez Marina do Rosario Lima $^{3}$
}

\begin{abstract}
RESUMO
O presente estudo, realizado durante o contexto de isolamento social de 2020, demandado por medidas preventivas contra o novo coronavírus, objetivou analisar as percepções de estudantes de Graduação que tiveram suas atividades deslocadas da modalidade presencial para a remota. Participaram da pesquisa 13 licenciandos em Matemática, manifestando-se a respeito das interações pedagógicas realizadas exclusivamente por meio das tecnologias digitais de informação e comunicação. As informações coletadas foram analisadas a partir das teorias de Seymour Papert e John Dewey, entre outros, por meio da Análise Textual Discursiva, em um movimento de desconstrução e reconstrução de ideias. Emergiram, então, duas categorias representativas das percepções discentes acerca das alterações de formato impostas, e essas categorias mostram que os acadêmicos compreenderam a situação vivida e buscaram o enfrentamento das dificuldades que surgiram, mas, entretanto, fizeram questão de evidenciar que sentiram falta de interações dialógicas in loco e que preferem aulas presenciais.
\end{abstract}

Palavras-chave: Tecnologias Digitais de Informação e Comunicação; ensino e aprendizagem; interação social.

\section{SOCIAL ISOLATION: PERCEPTIONS FROM THE STUDENTS ABOUT THE CHANGE OF ACADEMIC INTERACTIONS TO DIGITAL MEDIA}

\begin{abstract}
The present study, carried out during the social isolation context of 2020 , required by preventive measures against the covid-19, aimed to analyze the perceptions of the students who had their activities moved from the presential practice for a distance learning context. Thirteen mathematics students participated in the study, expressing themselves about the use of the digital information and communication technologies in the teaching and learning processes. The collected information was analyzed with Seymour Papert e John Dewey theories, among others, through the Discursive Textual Analysis from a deconstruction and reconstruction movement of ideas. Emerged two representative categories of student's perceptions about the format changes imposed and these categories point out that the students understood the situation and tried to face the new difficulties. Otherwise, they evidenced that missed the in loco dialogical interaction and that they prefer presential classes. Keywords: Digital Information and Communication Technologies; teaching and learning; social interaction.
\end{abstract}

Recebido em: $24 / 5 / 2020$

Aceito em: 21/6/2020

\footnotetext{
1 Autor correspondente. Instituto Federal Farroupilha, Campus Alegrete. RS 377, km 27 - Passo Novo. Alegrete/RS, Brasil. CEP 97555-000. http://lattes.cnpq.br/9132104547468000. https://orcid.org/0000-0002-9573-8053. rafael.bueno@iffarroupilha.edu.br

2 Prefeitura Municipal de Uruguaiana/RS, Brasil. http://lattes.cnpq.br/7430670847562236. https://orcid.org/0000-0001-7946-8842.

3 Pontifícia Universidade Católica do Rio Grande do Sul - PUC. Porto Alegre/RS, Brasil. http://lattes.cnpq.br/4171062268615605. https:// orcid.org/0000-0002-2676-5840.
} 


\section{INTRODUÇÃO}

São numerosas as pesquisas realizadas que ressaltam a importância da introdução das Tecnologias Digitais de Informação e Comunicação (TDIC) no contexto educacional, sobretudo nos cursos de Graduação (PONTE, 2000; PIMENTEL, 2016; KRIPKA; VIALI; LAHM, 2019; VALENTE, 2019). No ano de 2019 a Organização das Nações Unidas para a Educação, a Ciência e a Cultura (Unesco) publicou a terceira versão do seu marco de competências docentes em matéria de incorporação dos novos recursos tecnológicos às práticas pedagógicas. No documento, a utilização eficaz e inovadora desses recursos é apontada como papel do educador contemporâneo com vistas à promoção da aprendizagem dos estudantes.

Nesse sentido, entende-se a necessidade de repensar os espaços formativos atuais em busca da criação de intersecções pedagógicas capazes de catalisar o processo de construção do conhecimento com o apoio das Tecnologias Digitais da Informação e Comunicação (TDIC). Tal necessidade torna-se ainda mais premente quando se percebe que a vida dos jovens atuais, considerados nativos digitais, está tão vinculada às TDICs que é insensato para um professor tentar competir com as mídias digitais e as redes sociais.

Nesse contexto, há, por parte dos autores deste artigo, todos docentes, motivação e esforço contínuos para introduzir as TDICs de forma enriquecedora e motivadora em suas ações pedagógicas. Em virtude da pandemia do novo coronavírus, entretanto, as aulas sob sua responsabilidade tiveram de ser, em março de 2020, abruptamente deslocadas dos tradicionais ambientes presenciais de interação, permeados pelas TDICs, para, exclusivamente, Ambientes Virtuais de Ensino e de Aprendizagem (Avea) ${ }^{4}$.

Dessa forma, essa investigação recai sobre a experiência, a partir dessa nova realidade, de 13 alunos de duas turmas de um curso de Licenciatura em Matemática, os quais contaram com a docência de um dos autores deste trabalho. Assim, tem-se como objetivo da presente pesquisa investigar o que se mostra da percepção desses estudantes sobre o deslocamento das interações acadêmicas para os meios inteiramente digitais.

O presente texto descreve o percurso traçado nesta pesquisa em seis seções. $\mathrm{Na}$ primeira, contextualiza-se o tema proposto, justificando o interesse dos autores, e descreve-se o objetivo da investigação. Na segunda seção são abordadas as opções metodológicas adotadas, buscando-se evidenciar as características, as etapas da pesquisa e os passos dados no processo de Análise Textual Discursiva (ATD). Na terceira seção os sujeitos da pesquisa são caracterizados e as impressões inicias são construídas. A quarta e a quinta seções trazem as imagens construídas pelos autores, por meio da ATD, sobre o fenômeno estudado. Na última seção são feitas, então, as considerações finais sobre a pesquisa realizada.

Espaços virtuais que se transformam em ambientes educativos nos quais alunos e professores se comunicam e interagem por meio de interfaces como chats, fóruns de discussão, mensagens individuais ou coletivas, entre outras ferramentas colaborativas (ALVES; HECKLER, 2018). 


\section{PERCURSOS METODOLÓGICOS}

A pesquisa científica tende a transcender o senso comum, conforme argumenta Deslandes (2002), por meio do método científico, que permite a interpretação da realidade como fonte de conhecimento, unindo, dialeticamente, o teórico e o empírico. De acordo com Minayo (2002), a metodologia também inclui as concepções teóricas de abordagem, um conjunto de técnicas que viabiliza essa percepção do real e o potencial criativo dos pesquisadores.

Partindo dessas concepções sobre metodologia e do objetivo desta investigação, adota-se uma análise qualitativa para o percurso desta pesquisa. Sendo assim, admite-se, concordando com Borba (2004), que as interpretações trazidas sofrem, de forma explícita, interferência subjetiva, de modo que o conhecimento construído é visto sempre como uma compreensão contingente, negociada, e não como uma verdade absoluta.

Nesse contexto, a análise qualitativa proposta é desenvolvida por meio da Análise Textual Discursiva (ATD). Moraes e Galiazzi (2016) a definem como um método qualitativo de análise de informações que busca produzir novas compreensões sobre fenômenos e discursos. Por meio da sua utilização, a pesquisa desprende-se do reducionismo epistêmico, caracterizado pelo tradicional esquema sujeito-objeto, ainda fortemente presente nas investigações envolvendo as ciências naturais (SOUSA; GALIAZZI, 2018). Sendo assim, partindo de uma descrição do fenômeno analisado, conforme afirmam Ariza et al. (2015), almeja-se a compreensão, a partir de uma abordagem hermenêutica, dos discursos produzidos pelos sujeitos dessa investigação.

Ressalta-se, entretanto, que esse percurso é traçado com o intento de distanciar a interpretação construída de uma simples descrição que, conforme argumentam Sousa e Galiazzi (2018, p. 806), "remete à ideia de um jogo de quebra-cabeça, cuja paisagem já está definida a priori, exigindo do jogador encontrar as peças certas a serem colocadas em seus devidos lugares".

Dessa forma, com horizontes abertos, modificando as peças do jogo e deixando de lado a ideia de um quebra-cabeça, percorrem-se as etapas da ATD. É construído, então, um panorama que remete, de acordo com a Figura 1, à ideia de um mosaico, entendido como uma forma mais coerente de refletir a imagem do fenômeno estudado a partir das lentes dos pesquisadores.

Figura 1 - Diferentes imagens construídas com as mesmas peças de um mosaico
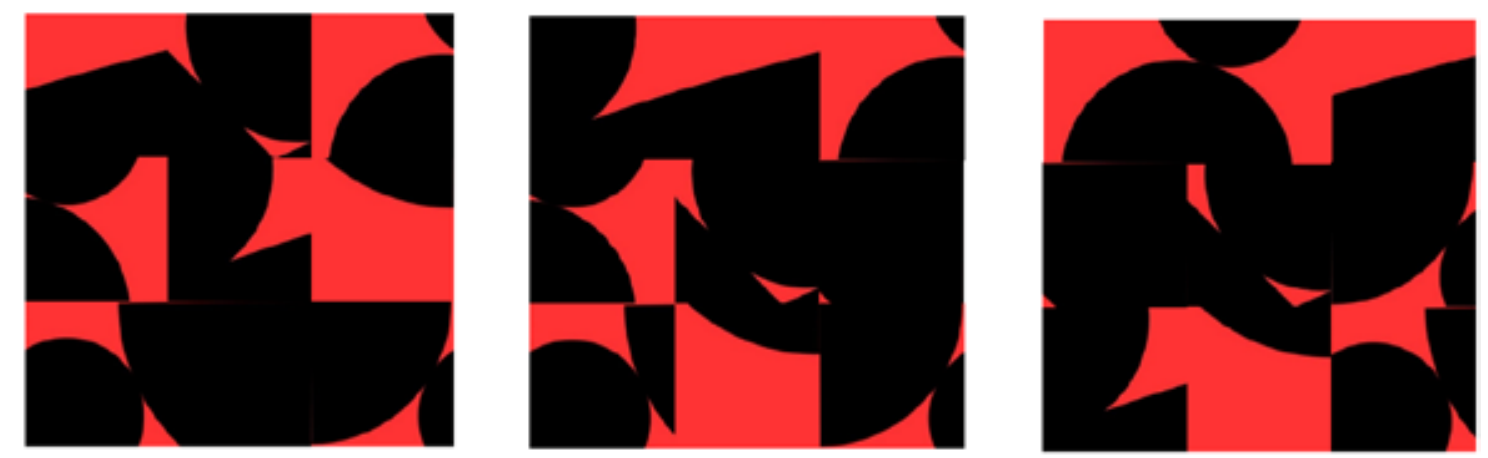

Fonte: Elaboração própria. 
Nesse sentido, conforme preconizam Galiazzi e Sousa (2019, p. 19),

Durante toda a análise, a ênfase é dada à interpretação, à valorização do conhecimento do pesquisador, à escuta do que se mostra nas informações, à natureza histórica das informações, à linguagem em direção a novas compreensões. É um processo que exige esforço e envolvimento. Enfatizar esses aspectos é retomar muitas vezes a etapas anteriores da análise.

Nessa perspectiva, seguindo os passos sugeridos por Moraes (2003), ideias são construídas por meio de uma sequência recursiva, composta por três momentos: a unitarização, a categorização e a construção de metatextos.

Inicia-se, portanto, pela unitarização, que se constitui na desconstrução dos textos analisados, de forma que breves fragmentos recebem títulos representantes do tema central de cada trecho. Nessa etapa, interpretações pessoais são assumidas, pois, no processo de análise, conforme ressaltam Galiazzi e Sousa (2019), a ordem e a desordem caminham juntas e se produzem, nessa presença mútua, pelas teorias que organizam o pensamento dos pesquisadores e que, portanto, não podem ser simplesmente subtraídas da ATD.

Passa-se, então, para a categorização, em que, de acordo com Paula, Menezes e Guimarães (2015), busca-se definir e classificar as categorias emergentes que surgem das unidades de sentido. Conforme preconizam Moraes e Galiazzi (2016), essa construção implica um processo de comparação e contraste entre as unidades de análise, no qual são organizados conjuntos com elementos semelhantes com base no referencial teórico da investigação e na perspectiva dos pesquisadores. Nesse contexto,

O sentido dado à palavra emergência é aquele da compreensão que surge durante o processo de análise, que o pesquisador, como sujeito histórico, percebe, o que o leva a uma teoria não antes conhecida, mas parte das suas preconcepções (SOUSA; GALIAZZI, 2018, p. 809).

Ressalta-se que o conjunto de categorias resultante pode ser entendido como o arcabouço teórico que ajuda os pesquisadores a compreender o fenômeno investigado e que exige uma transcendência do operativo em direção a um modo mais perceptivo, intuitivo e hermenêutico de análise. Dessa forma, o processo de categorização descreve uma sequência de estágios classificatórios. Essa sequência aponta para um conjunto de categorias, cada uma reunindo os seus elementos semelhantes (GALIAZZI; SOUSA, 2019).

Finalmente, chega-se à construção dos metatextos, que inicia com a descrição de cada categoria estabelecida, passa por uma interpretação ampla dessas categorias e chega à criação de argumentos aglutinadores. Conforme destacam Bueno, Ballejo e Viali (2020), cada metatexto é formado por trechos de narrativas dos sujeitos, pela análise e interpretação dos pesquisadores e por teorização fundamentada nas ideias discutidas ao longo da investigação. Nesse sentido, Paula, Menezes e Guimarães (2015, p. 31) destacam:

A interpretação que advém da relação entre as categorias é múltipla, podendo ser atribuídos os mais variados e diferentes significados nessa interpretação. $O$ que faz com que o pesquisador opte por determinadas relações é decorrente do objetivo da pesquisa e do aporte teórico que está sendo utilizado. 
Percebe-se que a ATD exige teoria. A teoria demandada nesse processo, no entanto, precisa se mostrar em movimento epistêmico com os próprios pesquisadores. Sendo assim, as categorias emergentes surgem como uma compreensão construída durante a análise, a partir das perspectivas dos investigadores, entendidos como sujeitos históricos, submetidos a um contexto social e que, portanto, partem, necessariamente, das suas concepções singulares para alcançar novas ideias cientificamente aceitas (SOUSA, GALIAZZI, 2018).

\section{CARACTERIZAÇÃO DOS SUJEITOS E IMPRESSÕES INICIAIS}

A partir do panorama metodológico adotado para a investigação destaca-se o campo empírico estudado, que abrange os argumentos trazidos por 13 alunos de um curso de Licenciatura em Matemática, de uma instituição de ensino do Estado do Rio Grande do Sul, sobre o deslocamento das interações acadêmicas para meios inteiramente digitais em razão da pandemia que assolou o mundo em 2020. Os acadêmicos, com idades entre 19 e 38 anos, faziam parte das turmas Cálculo II e Equações Diferenciais Ordinárias (EDO), mutuamente exclusivas, ambas sob responsabilidade de um dos autores deste trabalho.

Com o objetivo de contextualizar a situação vivida, destaca-se que o curso de Licenciatura em Matemática, do qual participam esses acadêmicos, ocorre na modalidade presencial de ensino. Sendo assim, o primeiro semestre de 2020 iniciou normalmente, em meados de fevereiro, com encontros realizados no campus da instituição. As aulas in loco ocorreram, então, até a segunda semana de março, quando, de forma abrupta e, portanto, inesperada, as atividades presenciais foram suspensas pela suspeita de contaminação de um colaborador.

Após quatro encontros realizados em espaços físicos no campus da instituição, as aulas foram deslocadas, então, para meios exclusivamente digitais, sendo denominadas pela reitoria de aulas remotas. Nesse novo contexto, as atividades pedagógicas foram realizadas durante os dois meses seguintes, sendo encerradas no dia 14 de maio em razão do limite legal de encontros a distância permitidos para cursos presenciais de Graduação.

Assim, utilizando o Avea da instituição como referência dessas atividades, textos explicativos, elaborados pelo professor, sobre os conceitos estudados nas disciplinas, foram disponibilizados para os estudantes a cada semana. Ademais, foram propostos trabalhos individuais e em grupos, e também exercícios, que eram resolvidos pelo docente em vídeos, os quais eram, então, anexados ao espaço das turmas no Avea. Além disso, foram disponibilizados fóruns para cada tópico estudado, a fim de que pudesse haver troca de ideias entre os estudantes e entre a turma e o docente.

O princípio dessas ações norteava-se pela ideia, sugerida pela direção de ensino da instituição, de evitar a necessidade de sincronia, de forma que houvesse mais liberdade para os acadêmicos adaptarem seus estudos e seu tempo à nova realidade. Após, entretanto, um encontro realizado ao vivo com o recurso Google Meet, na segunda semana de isolamento social, os discentes entenderam, em conjunto, que essa interação simultânea, na qual todos podem compartilhar um mesmo momento, era importante para a construção de seus conhecimentos. Foi dessa forma, então, com encontros semanais intermediados pelo Google Meet, que as disciplinas de Cálculo II e EDO se desenvolveram durante o período de quarentena em que houve aulas remotas. 
Findado esse espaço de tempo, caracterizado por essas ações de ensino e aprendizagem realizadas exclusivamente por meio das TDICs, os acadêmicos foram convidados a responder um questionário composto por cinco perguntas e que versava sobre a sua experiência com as aulas remotas. Incialmente, os discentes foram questionados sobre a sua satisfação com as interações realizadas nesse período. Conforme mostra a Figura 2, pode-se entender que eles se sentiram satisfeitos com as atividades que foram desenvolvidas no período de quarentena.

Figura 2 - Satisfação dos acadêmicos com as aulas remotas

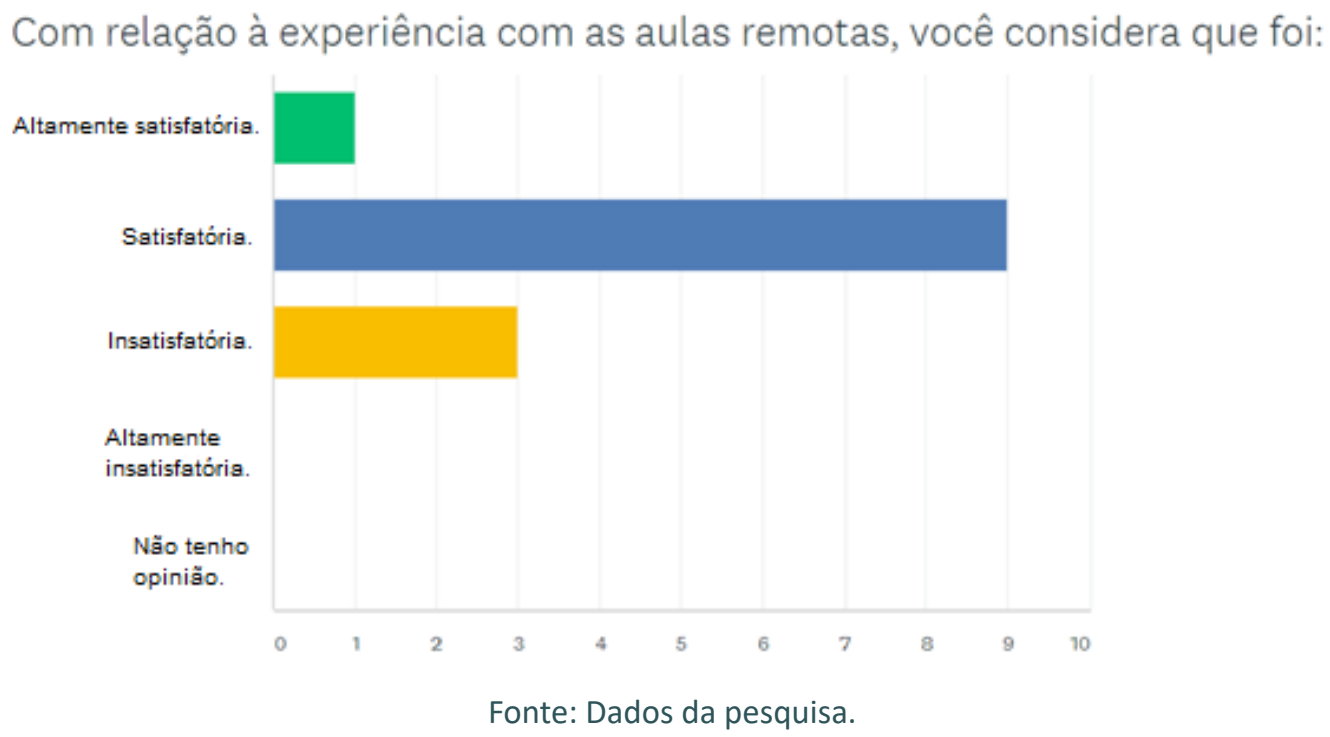

As respostas dadas à questão seguinte mostram que a maior parte dos discentes (10) acredita que as aulas a distância contribuíram para a construção dos conceitos das disciplinas de Cálculo II e EDO. Incitados a comparar os espaços formativos, entretanto, a grande maioria afirmou, de acordo com o que ilustra a Figura 3, que prefere as aulas presenciais em detrimento dos encontros promovidos pelos meios digitais.

Figura 3 - Preferência dos acadêmicos sobre espaços formativos

Comparando as aulas presenciais com as aulas remotas, você diria que prefere:

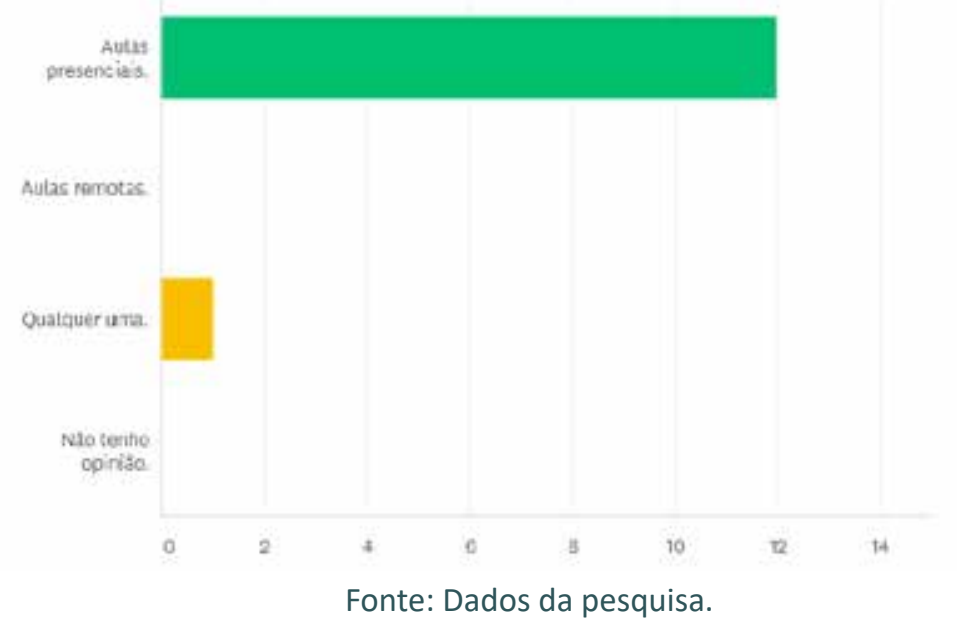

Contexto \& Educação

Editora Unijuí •ISSN 2179-1309 • Ano 36 • no 115 • Set./Dez. 2021 
As duas últimas perguntas trazidas aos discentes solicitavam respostas discursivas. Propunham, nesse contexto, que os acadêmicos trouxessem seus discursos, posições e argumentos sobre a sua experiência com as aulas remotas.

Para analisar essas respostas utilizou-se, então, a ATD. Dessa forma, a partir das categorias emergentes, descritas por Moraes e Galiazzi (2016) como pontes que possibilitam a auto-organização da compreensão do fenômeno sobre o qual se debruça o trabalho investigativo, foram construídos dois metatextos, intitulados Compreensão $e$ enfrentamento das dificuldades e Necessidade de interação dialógica presencial. Para manter o anonimato dos sujeitos da pesquisa eles são identificados, nos metatextos, por E1, E2, E3, (...), E13.

\section{Compreensão e Enfrentamento das Dificuldades}

A análise dos dados coletados nesta investigação acerca das experiências discentes a partir de aulas remotas, apesar de revelar inúmeras dificuldades, evidenciou reiteradas manifestações envolvendo uma postura de compreensão ante o novo contexto imposto pela situação pandêmica ocorrida no ano de 2020. Tais manifestações justificam, portanto, a presente categoria emergente e a organização das ideias que são discutidas a seguir.

O caráter imperativo e emergencial que determinou a alteração de formato das aulas (não apenas nesse curso, mas em qualquer espaço formativo presencial) foi destacado pelos estudantes. Dessa forma, E4 analisou a migração para as aulas remotas como uma "questão de necessidade". E5 ressaltou que "as aulas remotas não foram uma escolha por questões de gosto, mas algo que foi imposto" a todos, em virtude de uma nova realidade global.

Os sentimentos de compreensão e resiliência perante as mudanças demandadas pelo risco de infecção pelo coronavírus ficam latentes, também, quando E5 afirma: “[...] atualmente estamos vivendo em tempos difíceis para que haja aulas presenciais. Devemos prezar pela nossa saúde e pela saúde dos que amamos". Sendo assim, percebe-se que uma importante dimensão formativa ganha relevo junto aos acadêmicos, uma vez que "a educação deve formar cidadãos comprometidos com a construção de uma sociedade mais digna, justa e democrática" (MARTINS, 2017, p. 67).

No momento em que a impossibilidade de aulas presenciais é compreendida, as aulas remotas despontam como uma alternativa possível para a continuidade dos processos de ensino e de aprendizagem em andamento nas disciplinas. Nesse contexto emergente, as TDICs surgem, portanto, como ferramentas capazes de viabilizar essa mudança.

Apesar da conformidade em relação às novas determinações para condução dos estudos, variadas foram as demonstrações relacionadas às dificuldades enfrentadas durante o processo de transição. Nesse sentido, ainda que sem detalhar aspectos que influenciaram negativamente o acompanhamento das aulas remotas, E7 destaca que, no seu caso, "foi uma guerra e a adaptação foi muito difícil". 
Essas e outras declarações revelam uma falta de familiaridade de alguns estudantes com as ferramentas digitais. Transparece, então, conforme destaca Pimentel (2016, p. 497), "a existência de duas gerações bem definidas do ponto de vista de familiaridade com essas ferramentas. Uma delas são os nativos digitais e a outra os imigrantes digitais".

A dificuldade referida por alguns acadêmicos é agravada, ainda, por questões que se referem a problemas de acesso à World Wide Web. Dessa forma, E9 salienta que "em diversos momentos a minha internet caía e, assim, não aprendi quase nada". Essa afirmação leva a uma consideração sobre os contextos sociais nos quais estão inseridos os discentes, que não constituem um conjunto homogêneo de sujeitos. Reflexões sobre as condições de acesso às TDICs devem, portanto, figurar entre as preocupações que complexificam ainda mais o panorama traçado.

Os discentes também citaram outras dificuldades específicas enfrentadas durante o transcorrer dos estudos remotos. Entre elas destacaram-se questões atinentes à credibilidade e à seleção das fontes de busca de informações alternativas na internet. A esse respeito, E5 exemplifica que "cada canal do YouTube que olhava para tirar dúvidas falava uma coisa diferente do outro".

Nesse contexto, concorda-se com o filósofo Dewey (1979, p. 70), quando assevera que "as informações, em seu simples caráter de informações, não constituem um meio especial de exercitar-se a capacidade intelectual". Em convergência, destaca-se que a finalidade da educação não se resume meramente a integrar os indivíduos na chamada sociedade da informação, mas inclui formar espíritos críticos que saibam escolher as informações que precisam para construir significados e conhecimento (PIMENTEL, 2016). Esse é mais um desafio que decorre da utilização das TDICs e que exige preparação dos agentes educacionais.

A ausência da figura do professor também constou entre as questões pontuadas como aspectos que interferiram negativamente nos processos de ensino e de aprendizagem. Nesse sentido, E9 escreveu que "não é como nas aulas presenciais que a todo o momento o professor está junto, explicando e tirando dúvidas". Ratificando essa percepção, E8 entende que as "aulas presenciais possibilitam um maior acesso para sanar as dúvidas". Em movimento convergente, o depoimento de E6 complementa essa ideia indicando que, nas aulas remotas, "às vezes uma simples dúvida pode se tornar um pesadelo".

Emergem, também, problemas relacionados ao desenvolvimento do pensamento crítico e da autonomia. Tais problemas culminaram, nessa situação específica, com a demonstração de sentimentos de insegurança e receio do novo, decorrentes da submissão ao diferente formato imposto. Alguns estudantes manifestaram essas impressões. E13, por exemplo, relatou: "[...] as aulas presenciais me dão mais segurança". E5 destaca o caráter inédito da experiência ao afirmar que "quanto às questões de aprendizado, é uma forma diferente, com a qual nunca havia tido contato".

Cabe destacar, ainda, que o professor das disciplinas vivenciou experiências desafiadoras advindas das mudanças estabelecidas nesse período, de forma que foi necessário um redimensionamento das suas concepções epistemológicas (FLORES; LIMA; MÜLLER, 2018). Concordando com Alves e Heckler (2018, p. 15), entende-se que para 
trabalhar com ensino a distância "se faz necessário o desenvolvimento de estudos relacionados à didática, ferramentas de ensino e modelos pedagógicos adequados para a referida modalidade".

Assim, a abertura para o novo e a necessidade de reinventar-se e de aprender com as novas possibilidades sintetizam algumas das demandas docentes desse período de adaptação e transformação. Nesse contexto, destaca-se, de forma inconfundível, que

A habilidade mais importante na determinação do padrão de vida de uma pessoa já se tornou a capacidade de aprender novas habilidades, de assimilar novos conceitos, de avaliar situações, de lidar com o inesperado (PAPERT, 1994, p. 5).

No caso específico das transformações das situações de ensino e de aprendizagem enfocadas, a conectividade e a comunicação pareceram ser facilitadas por meio da realização de videoconferências. Diversos estudantes referiram-se a essa estratégia como benéfica para a construção do novo ambiente educativo. E3 destaca que "as aulas remotas começaram a fazer sentido a partir das videoconferências", citando essa proposta de interação como um marco importante a partir do qual as atividades se tornaram mais interessantes e profícuas. Corroborando essa ideia, E2 expressou que "da maneira que o professor realizou, fazendo videoconferência, ficou bem mais tranquilo".

Essa proposta de interação virtual apresentou-se como um recurso fundamental no período, pois possibilitou a ocorrência de aulas remotas síncronas, proporcionando uma aproximação entre professor e acadêmicos. Assim, as características desse recurso possibilitado pelas TDICs resgataram, de alguma forma, o aspecto coletivo das construções.

Nesse contexto, E12 pontua que "apesar da distância, o grupo se uniu muito para se ajudar", e E7 reforça essa impressão ao afirmar que contou "com a ajuda dos colegas". Percebe-se, portanto, uma união da turma na busca pela transposição das adversidades, o que caracteriza uma importante dimensão do processo de formação para a vida em coletividade, uma vez que, conforme destaca D'Ambrosio (1997, p. 70), "a educação é a estratégia definida pelas sociedades para levar cada indivíduo a desenvolver seu potencial criativo e para desenvolver a capacidade dos indivíduos se engajarem em ações comuns".

Dessa forma, a aprendizagem acaba abrangendo diferentes e importantes enfoques, pois passa a ser centrada no aluno, no professor e na conectividade, alcançando uma dimensão social. A formação implica também em aprender em comunidade e ser capaz de contribuir com a construção coletiva do conhecimento (ALMENARA, 2015).

Os argumentos trazidos pelos discentes abrangem, em seu cerne, aspectos relacionados à importância do dialogismo, possibilitado pela presença de interlocutores que, mesmo a distância, contribuem com troca de ideias, pontos de vista, complementações e, inclusive, contrapontos às discussões propostas. A alteridade, ou seja, a presença do outro, ainda que de forma virtual, mostrou-se fundamental para a constituição própria de ideias e para a busca de caminhos alternativos a serem traçados. 
E6 detalha a rota encontrada para facilitar a sua experiência com aulas remotas, contando que buscou "assistir videoaulas e pesquisar sobre o assunto ou até mesmo trocar ideia com algum colega, tornando tudo mais fácil". Nesse sentido, E7 manifesta aspectos positivos do período de aulas remotas: "[...] acabei aprendendo muito com as aulas on-line e também aprendi a usar ferramentas que eu nem conhecia".

Apesar da compreensão da necessidade da experiência com as aulas remotas, do esforço do docente, do engajamento para a aprendizagem a partir desse formato e, inclusive, da citação de seus efeitos positivos, os acadêmicos destacaram, reiteradamente, a vinculação dessa experiência a um caráter excepcional e salientaram a necessidade de sua duração ser restrita. Por exemplo, E4 refere que não aprova esse tipo de interação "para estudos contínuos"; E11 destaca: "[...] é de extrema importância afirmar que prefiro aulas presenciais"; e E5 afirma que "teria aprendido mais se tivesse aula presencial". Sendo assim, aspectos atinentes às especificidades das aulas presenciais são discutidos na categoria a seguir.

\section{Necessidade de Interação Dialógica Presencial}

Na categoria discutida no metatexto apresentado na seção anterior, a preferência pela modalidade presencial de estudos foi sinalizada pelos acadêmicos. Cabe, nesse espaço, portanto, enfatizar o motivo que fundamenta tal posição a partir da percepção dos pesquisadores sobre a ótica dos sujeitos desta investigação.

A necessidade de interação dialógica presencial é que embasa a presente categoria emergente por consistir em aspecto relevante e presente em diversas manifestações dos estudantes. Os futuros docentes destacaram como importante demanda, atrelada ao ensino e à aprendizagem, o estabelecimento de trocas síncronas, mais frequentes e de melhor qualidade entre professor e alunos.

Quanto à comunicação entre os agentes educacionais, alguns estudantes expressaram dificuldades relacionadas à falta de compreensão no envio ou na recepção das mensagens. Esse ruído comunicacional (de formulação ou interpretação) foi destacado por E5, ao citar que "o mais difícil é não ter o auxílio presencial do professor, pois pelo e-mail ou pelo WhatsApp não fica tão claro", e por E4, ao argumentar que "nos momentos em que surgiam as dúvidas as comunicações para esclarecimentos não eram tão proveitosas".

Essas dificuldades, percebidas pelos licenciandos, lançam luzes sobre a relevância das diversas formas de linguagem nas interações sociais que visam à aprendizagem. A esse respeito, de acordo com Di Fanti (2003, p. 98),

[...] temos de considerar que o outro, no movimento dialógico, não é somente o interlocutor imediato ou virtual. É muito mais. O outro projeta-se a partir de discursos variados (passados, atuais, presumidos). São as outras vozes discursivas posições sociais, opiniões - que vêm habitar de diferentes formas o discurso em construção.

A percepção da importância da adequação da linguagem e da necessidade de maior detalhamento na expressão de pensamentos sujeitos a interpretações diversas configura-se, portanto, em aspecto fundamental a ser sopesado em ambientes de aprendizagem, em especial nos Aveas que parecem abrigar pontos ainda mais sensíveis. 
Além da qualidade, a frequência das trocas entre professor e alunos também foi apontada. Nesse sentido, E7 destacou esse aspecto como uma dificuldade relacionada às aulas remotas, pois "faltou o diálogo durante as atividades em si. Para mim, tem que ser presencial, pois o debate e as perguntas saem na hora". Corroborando essa ideia, E10 argumenta que "fez falta a troca de opiniões e conhecimentos que se tem numa aula presencial". Entende-se, portanto, que, com o cenário estabelecido, "os laços inter-humanos, que antes teciam uma rede de segurança [...] se tornam cada vez mais frágeis e reconhecidamente temporários" (BAUMAN, 2007, p. 9).

Traçando uma rota alternativa, também é preciso conceber que a construção de conhecimento pode ser subsidiada tanto em aulas presenciais quanto em atividades remotas. Essa percepção manifesta a necessidade de que também os estudantes, principalmente os do Ensino Superior, revisem suas percepções acerca das possibilidades que envolvem o ensinar e o aprender, assumindo-se como sujeitos mais ativos e atores principais da sua evolução cognitiva. Nesse sentido, os discentes podem passar a ser, de acordo com Almenara (2015), investigadores, usuários das tecnologias, pensadores, criadores de sentido, agentes transformadores do mundo e, de alguma forma, professores de si mesmos.

Outros entendimentos referentes à aprendizagem e considerados incompatíveis com a construção da autonomia discente advieram da escrita dos estudantes. Nesse sentido, E4, por exemplo, traz como aspecto negativo, atrelado ao ensino remoto, o fato de que nele "as dúvidas não são respondidas instantaneamente". Tal manifestação deixa transparecer a percepção de que o docente é o único detentor dos saberes e se defronta com a ideia de que, conforme destaca Papert (1994, p. 125), "o tipo de conhecimento que as pessoas mais precisam é aquele que lhes ajudará a obter ainda mais conhecimento".

A noção da importância da autonomia na aprendizagem não parece ser partilhada por E3, que lembra ter sentido "dificuldade no momento da resolução dos exercícios, pois o professor não estava presente para tirar as dúvidas". Entende-se que tal afirmação pode colocar em análise o papel do professor, do aluno e da dúvida na construção do conhecimento.

Nessa perspectiva, Dewey (1979) destaca que é importante deixar o próprio aluno encontrar seus erros e procurar corrigi-los. Assim, a função docente centra-se mais em prover condições e materiais próprios para dirigir a curiosidade orgânica dos acadêmicos rumo a investigações que tenham um fim educativo e produzam, enfim, resultados positivos na construção do conhecimento.

Entende-se que a oportunidade de cometer erros é importante na educação; não porque os erros são desejáveis, mas porque o excesso de zelo em selecionar atividades e materiais que praticamente impedem qualquer possibilidade de equívoco restringe a iniciativa e a autonomia, reduz o julgamento crítico ao mínimo e acaba incentivando o uso de métodos que se distanciam das situações complexas da vida real (DEWEY, 1979). Dessa forma, Papert (1994, p. 147) argumenta: 
O estado normal do pensamento é estar fora de curso o tempo inteiro e fazer correções que retrocedem o suficiente para continuar andando numa direção globalmente satisfatória. Esse tipo de pensamento está sempre vagamente certo e vagamente errado.

Nesse contexto percebe-se a carência de interação presencial dialógica sentida pelos acadêmicos e nota-se, além da necessidade de visualização das linguagens características de aulas presenciais, uma interpretação do ensino ainda centrada no professor. Sendo assim, Papert (1994) sugere a relevância das TDICs para a construção de ambientes virtuais que possam trabalhar com uma epistemologia de incertezas administradas.

Entende-se, entretanto, que essa falta de autonomia pode ter sido catalisada pelo caráter emergencial da mudança de paradigma de interação e também pela impossibilidade de criação adequada, baseada em reflexões consistentes e graduais de pedagogias próprias para o ensino não presencial. Ressalta-se, assim, que para o trabalho docente com o ensino a distância é preciso desenvolver alternativas didáticas, estudar novas ferramentas educacionais e construir modelos pedagógicos próprios.

\section{CONSIDERAÇÕES FINAIS}

A partir da análise dos argumentos dos acadêmicos, construída por meio da ATD, pode-se perceber que os estudantes compreenderam a situação excepcional de isolamento social imposta em razão da pandemia do novo coronavírus. Ademais, foram receptivos e se abriram para as aulas remotas, buscando estudar e construir conhecimento, tendo como referência a comunicação mediada exclusivamente pelas TDICs.

Fica evidente, contudo, que os discentes sentiram falta de interação presencial dialógica. Por não terem experiência com a educação a distância, nem intenção de adotar essa modalidade na sua formação, sentiram-se isolados. Isso ficou evidente nas suas repetidas afirmações de que surgiram dificuldades principalmente durante a resolução de situações-problema, as quais, na visão dos acadêmicos, requeriam trocas síncronas com os colegas e o docente. Obviamente, a falta de diálogo também pode ocorrer em aulas presenciais, mas percebe-se que a ausência de discussões produtivas fica mais evidente quando a interação ocorre apenas no mundo virtual.

Esse sentimento também pode ser interpretado como uma possível falta de autonomia dos estudantes e compreendido pelo caráter repentino da situação. Nesse sentido, entende-se que, além de essa mudança de perspectiva de ensino e de aprendizagem não ser espontânea e consentida, um panorama de aulas remotas requer reconfiguração de fundamentos pedagógicos, pois a educação a distância "tem um conjunto de fatores específicos que a constituem enquanto modalidade educativa" (ALVES; HECKLER, 2018, p. 20).

Nesse sentido, acredita-se que para trabalhar com o ensino e a aprendizagem mediados exclusivamente pelos recursos digitais, ou seja, com educação a distância, os professores necessitam de formação adequada para a apropriação de metodologias es- 
pecíficas e perspectivas de interação inteiramente diferentes. Ademais, faz-se necessária a construção de conhecimentos sobre como acontece o desenvolvimento de novas ideias e conceitos em interações feitas unicamente por meio de Avea.

Ressalta-se, ainda, que, apesar de toda a dedicação dos acadêmicos, que buscaram se adaptar à nova realidade, fica claro o condicionamento dessa posição ao caráter de excepcionalidade vivido. Sendo assim, mais da metade da turma fez questão de destacar que não concorda com esse cenário para períodos prolongados, e que prefere, sem dúvida alguma, as aulas presenciais.

Por fim, enfatiza-se o caráter singular de aulas remotas, mediadas exclusivamente pelas TDICs, que caracterizam um tipo de interação totalmente diferente da que ocorre presencialmente. Esse cenário fez surgir, provavelmente mais rápido do que ocorreria em condições usuais, a necessidade de se trabalhar com os professores, em exercício e em formação inicial, alternativas formativas para que compreendam as novas epistemologias necessárias para enfrentar esse tipo de situação e para que sejam capazes de se adequar ao que se apresenta, possivelmente, como parte do futuro do ensino e da aprendizagem global.

\section{REFERÊNCIAS}

ALMENARA, J. C. Reflexiones Educativas sobre las Tecnologías de la Información e la Comunicación (TIC). CEF, n. 1, 2015.

ALVES, C. C.; HECKLER, V. TDIC na formação de professores em ciências e matemática: interlocuções com estudos brasileiros. Revista Insignare Scientia, v. 1, p. 1-25, 2018.

ARIZA, L. G. A.; DIAS, V. M. T.; SOUSA, R. S.; NUNES, B. R.; GALIAZZI, M. C.; SCHMIDT, E. B. Articulações metodológicas da análise textual discursiva com o ATLAS.ti: compreensões de uma comunidade aprendente. In: CONGRESSO IBERO-AMERICANO DE INVESTIGAÇÃO QUALITATIVA, 4., 2015. Aracajú. Atas [...]. Aracajú, 2015. p. 346-351.

BAUMAN, Z. Tempos líquidos. Rio de Janeiro: Zahar, 2007.

BORBA, M. A pesquisa qualitativa em educação matemática. In: REUNIÃO ANUAL DA ANPED, 27., 2004. Caxambu. Anais [...]. 2004, Caxambu, MG.

BUENO, R. W. S.; BALLEJO, C. C.; VIALI, L. Entrando na zona de risco: utilizando as TDIC para ensino e aprendizagem de conceitos de estatística descritiva. Revista Sergipana de Matemática e Educação Matemática, n. 1, p. 71-88, 2020.

D’AMBROSIO, Ubiratan. Transdisciplinaridade. São Paulo: Palas Athenas, 1997.

DESLANDES, S. F. A construção do projeto de pesquisa. In: MINAYO, M. C. S (org.). Pesquisa social: teoria, método e criatividade. Petrópolis, RJ: Editora Vozes, 2002.

DEWEY, J. Como pensamos: como se relaciona o pensamento reflexivo com o processo educativo. São Paulo: Editora Nacional, 1979.

DI FANTI, M. G. A linguagem em Bakhtin: pontos e pespontos. Veredas, v. 7, n. 1, p. 95-111, 2003.

FLORES, J. B.; LIMA, V. M. R.; MÜLLER, T. J. O uso das Tecnologias da Informação e Comunicação no ensino de cálculo diferencial e integral: reflexões a partir de uma metanálise. In: Abakos, Belo Horizonte, v. 6, n. 2, 2018.

GALIAZZI, M. C.; SOUSA, R. S. A dialética na categorização da análise textual discursiva: o movimento recursivo entre palavra e conceito. Revista Pesquisa Qualitativa, São Paulo, v. 7, n. 13, p. 1-22, 2019.

KRIPKA, R. M. L.; VIALI, L. LAHM, R. A. Formação de professores e uso de TIC: desafios e possibilidades. In: SIMPÓSIO INTERNACIONAL EM EDUCAÇÃO E COMUNICAÇÃO, 6., 2019. Disponível em: https://proceedings.ciaiq.org/index.php/ciaiq2015/article/view/187.

MARTINS, M. R. A educação moral no contexto das sociedades complexas e plurais. 2017. Tese (Doutorado) - Unicamp, Campinas, 2017.

MINAYO, M. C. S. Ciência, técnica e arte: o desafio da pesquisa social. In: MINAYO, M. C. S (org.). Pesquisa social: teoria, método e criatividade. Petrópolis, RJ: Editora Vozes, 2002. 
MORAES, R. Uma tempestade de luz: a compreensão possibilitada pela análise textual discursiva. Ciência e Educação, n. 9, v. 2, p. 191-211, 2003.

MORAES, R.; GALIAZZI, M. C. Análise textual discursiva. 3. ed. Ijuí: Editora Unijuí, 2016.

PAPERT, S. A máquina das crianças: repensando a escola na era da informática. Porto Alegre: Artes Médicas, 1994.

PAULA, M. C.; MENEZES, A. L. S.; GUIMARÃES, G. T. D. Análise textual discursiva: possibilidades de imersão. In: GUIMARÃES, G. T. D. (org.). Resignificando os labirintos da pesquisa qualitativa: exercícios práticos de análise de discurso. Porto Alegre: EDIPUCRS, 2015.

PIMENTEL, N. As Tecnologias de Informação e Comunicação (TIC) no Ensino Superior: a utopia da inovação pedagógica e da modernização. In: Revista de Educação Pública, Cuiabá, v. 25, n. 59/2, 2016.

PONTE, J. P. Tecnologias da Informação e Comunicação na Formação de Professores: que desafios?. In: Revista Ibero-americana de Educação, Madrid, n. 24, 2000.

SOUSA, R. S.; GALIAZZI, M. C. O jogo da compreensão na análise textual discursiva em pesquisas na educação em ciências: revisitando quebra-cabeças e mosaicos. Ciência \& Educação, Bauru, v. 24, n. 3, 2018.

VALENTE, J. A. Tecnologias e educação a distância no Ensino Superior: uso de metodologias ativas na graduação. In: Trabalho \& Educação, v. 28, n. 1, p. 97-113, 2019. 